Research Article

\title{
Calculation of Active Earth Pressure for Narrow Backfill with a Curved Slip Surface
}

\author{
Zhihui Wang $\mathbb{C D}^{1,2}$ Aixiang $W u,{ }^{1,2}$ and Yiming Wang ${ }^{1,2}$ \\ ${ }^{1}$ Key Laboratory of High-Efficient Mining and Safety of Metal, Ministry of Education, \\ University of Science and Technology Beijing, Beijing 100083, China \\ ${ }^{2}$ School of Civil and Resources Engineering, University of Science and Technology Beijing, Beijing 100083, China \\ Correspondence should be addressed to Zhihui Wang; chihui_w@hotmail.com
}

Received 11 June 2019; Revised 25 August 2019; Accepted 1 October 2019; Published 24 October 2019

Academic Editor: Carlo Rainieri

Copyright () 2019 Zhihui Wang et al. This is an open access article distributed under the Creative Commons Attribution License, which permits unrestricted use, distribution, and reproduction in any medium, provided the original work is properly cited.

\begin{abstract}
A method was proposed to calculate the earth pressure from a cohesionless backfill with a high aspect ratio (ratio of height to width of retaining wall). An exponential equation of slip surface was proposed first. The proposed nonlinear slip surface equation can be obtained once the width and height of the backfill as well as the internal friction angle of the backfill were given. The failure surface from the proposed formula agreed well with the experimental slip surface. Then, the earth pressure was calculated using a simplified equilibrium equation based on the proposed slip surface. It is assumed that the minor principal stress of the backfill near the wall and at its corresponding slip surface where the depth is the same is the same. Thus, based on the vertical force balance of the horizontal backfill strip, assuming the wall-soil interface and the slip surface is in the limit equilibrium state, defined by the Mohr-Coulomb criterion, the differential equilibrium equation was obtained and numerically solved. The calculated results agreed well with the test data from the published literature.
\end{abstract}

\section{Introduction}

Retaining walls are widely used in slope protection engineering. The mechanical model of the retaining structure is also suitable for backfill stability assessment in underground mining [1-3] and storage bins in the warehouse. The calculation of the earth pressure on the retaining wall is essential for the economical and safe design of the retaining wall. The distribution of the active lateral earth pressure on the retaining wall may be affected by the movement mode of the wall, the backfilling property [4], and the geometric layout of the backfill. This paper focuses on the active earth pressure on a horizontally translating rigid vertical wall supporting a cohesionless backfill.

Among the methods for calculating active earth pressure, the theories of Rankine [5] and Coulomb [6] have been used widely. Both of them are based on a linear slip surface, and the obtained earth pressure distribution is also linear. However, due to the existence of wall-backfill friction, the slip surface is generally curved [7-9] and the lateral pressure distribution on the back of the retaining wall is curved as well [10-14].

Some researchers considered the resistance of wall-soil friction to backfill, known as arching effect. Handy [11] considered the friction between two vertical rough retaining walls and a cohesionless backfill. Then, the researcher proposed that the existence of wall-backfill friction causes a rotation of principal stress direction along the horizontal backfill layer. Furthermore, Handy [11] calculated the active earth pressure on walls based on an assumed minor principal stress trajectory with the shape of catenary. In addition to Handy [11], Paik and Salgado [15] assumed the arc-shaped minor principal stress trajectory to calculate the earth pressure; Goel and Patra [7] used the parabolic minor principal stress trajectory to calculate the earth pressure on the retaining wall from the cohesionless backfill. Khosravi et al. [4] also adopted the arc-shaped minor principal stress trajectory to obtain the two-dimensional analytical solution of the active earth pressure on the retaining wall based on the assumption that the vertical stress is uniformly distributed in 
horizontal direction. These methods for calculating active earth pressure all achieved good results with respect to experimental data.

Inspired by the method of minor principal stress trajectory, scholars have proposed some other different improvements to calculate earth pressure, such as improved slip surface shape and different stress trajectory shapes. For example, Rao et al. [16] utilized a new angle of the linear slip surface; Zhou et al. [17] adopted a parabolic stress trajectory; and Li and Wang [18] employed the linear minor principal stress trajectory.

However, the abovementioned methods generally calculate the earth pressure with the assumption that the shape of the slip surface is linear, which is different from the shape of the real slip surface. Moreover, the linear slip surface has requirements for the width of the backfill behind the wall. And in practice, the backfill may have a rather limited width and cannot develop the abovementioned linear slip surface $[9,19,20]$. Further, the adoption of various shapes of the minor principal stress trajectory in the calculation is cumbersome. There are many backfills with large aspect ratio of height to width in the actual project, known as narrow backfill, limited backfill, or confined backfill. In this case, the development of the slip surface is in a limited region. For this reason, based on a physical test [9] and inspired by Tsagareli [8], an exponential slip surface curve that is close to the actual slip surface was proposed. Then, based on the exponential slip surface, the method for calculating the earth pressure was proposed without relying on assumptions about the shape of the minor principal stress trajectory.

\section{Formula for Slip Surface in Narrow Cohesionless Backfill}

When calculating the earth pressure, determination of the boundary conditions of the stress is fundamental, and the determination of the stress boundary condition is related to the geometry of the boundary. In case of a vertical retaining wall supporting a horizontal backfill without a surcharge, scholars have proposed some different assumptions about the shape of slip surface, and they are shown in Table 1.

As can be seen from Table 1, different formulas for slip surface have different application conditions and the effects are different too. However, most of them are ideal linear slip surface, regardless of the width of the backfill of the wall. The log-spiral shape is complicated in calculation, and there is also a requirement for the filling width: the width of backfill should be no less than the minimum width to develop a spiral curve. Thus, further improvements are needed for the narrow backfill with a slip surface through the wall base and the wall top shown in Figure 1.

Yang and Tang [9] obtained slip surfaces of the cohesionless backfills with different geometric layouts under three movement modes of the retaining wall. The test results showed that the slip surface in active state is generally a curve passing through the wall base and its diagonal wall top, indicating that the development of slip surface is limited by the narrow backfill. The test results showed that only under the uniform translation mode can the slip surface be a nonlinear curve passing through the wall base and its diagonal vertex. And, if the motion mode is rotation about the top or the base, the slip surface is more irregular from a straight line to a nonlinear curve. The test data used were from the experimental tests simulating the active earth pressure caused by the uniform translation movement of the rigid wall. Therefore, the development of the slip surface under the circumstance of the narrow backfill with high aspect ratio of height to width should consider geometric layout of backfill. Thus, constraints of traditional formulas of parabolic and exponential forms should be improved, which are listed in Table 2.

Using the coordinate system shown in Figure 1, the expressions of ParaNew and ExpNew can be written as (1) and (2), respectively:

$$
\begin{aligned}
& y=\frac{H-W \tan \left(45^{\circ}+(\varphi / 2)\right)}{W^{2}} x^{2}+\tan \left(45^{\circ}+\frac{\varphi}{2}\right) x, \\
& y=C\left[3.6\left(\frac{\pi}{4}+\frac{\varphi}{2}\right)+0.5\right]^{x / C}-C,
\end{aligned}
$$

where $C$ is a constant with a dimension of length; $H$ and $W$ are the height and width of the narrow backfill, respectively; and $\varphi$ is the internal friction angle of the backfill. For comparison, the equations satisfying the conditions listed in Table 2 are shown in Table 3:

The parabolic and exponential slip surfaces proposed in this paper are for backfills with large aspect ratio. The parabolic equation can be obtained by simply substituting the height and width of a given backfill. However, the exponential slip surface involves complicated transcendental equations and cannot be represented by a simple general formula. Therefore, the following equation needs to be solved first to obtain the value of $C$ :

$$
H=C\left[3.6\left(\frac{\pi}{4}+\frac{\varphi}{2}\right)+0.5\right]^{W / C}-C
$$

and then $C$ is substituted into (2) to get the required formula for later calculation. The performance of the above equations is shown in Figure 2.

It can be seen from Figure 2 that the lower part of the parabola proposed by Goel and Patra [7] is in good agreement with the actual data [9] when the width of backfill is $0.36 \mathrm{~m}$, and the lower part of the straight line of Rankine is in good agreement with the actual data in the case of width $0.56 \mathrm{~m}$. Except that, the four curves of Coulomb, Rankine, ExpTsagareli, and ParaGoel are quite different from the actual slip surfaces. In contrast, the parabolic curves and the exponential curves proposed in this paper are closer to the experimental slip surfaces of three widths, especially the exponential curve. For this reason, adopting the exponential curve is more in line with the actual situation when the cohesionless backfill with a relatively large aspect ratio is in the active state.

Using the exponential curve, the sliding wedge width $L(y)$ at a given height $y$ can be calculated as 
TABLE 1: Various formulas for slip surface when in active state.

\begin{tabular}{|c|c|c|}
\hline References & Theoretical essentials of slip surface & Backfill conditions \\
\hline Coulomb [6] & $\begin{array}{l}\text { The slip surface is a straight line with the angle } \\
\arctan \left(\left(\sqrt{\tan ^{2} \varphi+(\tan \varphi / \tan (\varphi+\delta))}\right)+\tan \varphi\right) \text { from } \\
\text { the horizontal plane. }\end{array}$ & Surcharge-free, flat top, cohesionless or cohesive \\
\hline Rankine [5] & $\begin{array}{l}\text { The slip surface is a straight line with the angle }(\pi / 4+ \\
\qquad / 2) \text { from the horizontal plane. }\end{array}$ & Surcharge-free, flat top, cohesionless or cohesive \\
\hline Tsagareli [8] & The slip surface is an exponential curve. & Surcharge-free, flat top, cohesionless \\
\hline Goel and Patra [7] & $\begin{array}{l}\text { The slip surface is a parabolic curve that is diagonally } \\
\text { across the bottom and top. }\end{array}$ & Surcharge-free, flat top, cohesionless \\
\hline $\mathrm{Xu}$ et al. [21]; Xu et al. [22] & $\begin{array}{l}\text { The slip surface can be divided into a logarithmic } \\
\text { spiral segment and a Rankine straight segment. }\end{array}$ & Surcharge-free, flat top, cohesionless or cohesive \\
\hline Xie and Leshchinsky [23] & $\begin{array}{c}\text { The slip surface can be represented by a logarithmic } \\
\text { spiral. }\end{array}$ & Surcharge-free, flat top, cohesionless or cohesive \\
\hline Rao et al. [16] & $\begin{array}{l}\text { The slip surface is a straight line with the angle } \\
(\pi / 4)+(1 / 2) \arcsin (\sin \delta / \sin \varphi)+(\varphi-\delta / 2) \text { from the } \\
\text { horizontal plane. }\end{array}$ & Surcharge-free, flat top, cohesionless or cohesive \\
\hline Khosravi et al. [24] & $\begin{array}{l}\text { The shape of slip surface changes from log-spiral or } \\
\text { parabolic to planar as the "planar ratio of slip surface" } \\
\text { increases. }\end{array}$ & Surcharge-free, flat top, cohesionless \\
\hline
\end{tabular}

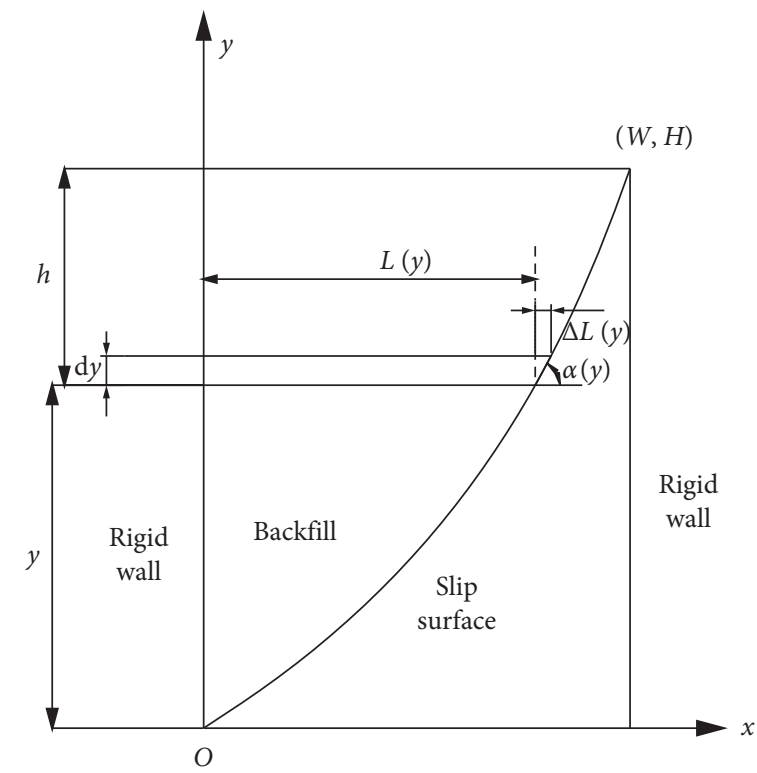

Figure 1: Geometric layout and coordinate system.

TABLE 2: Nonlinear sliding curves for comparison with test curves.

\begin{tabular}{|c|c|c|c|}
\hline Shape of slip surface & Notation in this paper & Constraint conditions of the curve & Reference \\
\hline Parabolic curve & ParaGoel & $\begin{array}{l}\text { The slip surface crosses the wall base point }(0,0) \text {, and } \\
\text { the tangent at this point is the Rankine slip surface. } \\
\text { The upper width of the sliding body is } 0.62 \text { times that } \\
\text { of Rankine's sliding body. }\end{array}$ & Goel and Patra [7] \\
\hline Parabolic curve & ParaNew & $\begin{array}{l}\text { The slip surface crosses the wall base point }(0,0) \text { and } \\
\text { wall top point }(W, H) \text {, and the tangent at this point is } \\
\text { the Rankine slip surface. }\end{array}$ & Proposed curve in this paper \\
\hline Exponential curve & ExpTsagareli & $\begin{array}{c}\text { The exponential slip surface crosses the wall base } \\
\text { point }(0,0) .\end{array}$ & Tsagareli [8] \\
\hline Exponential curve & ExpNew & $\begin{array}{l}\text { The exponential slip surface crosses the wall base } \\
\text { point }(0,0) \text { and wall top point }(W, H) \text {. }\end{array}$ & Proposed curve in this paper \\
\hline
\end{tabular}


TABLE 3: Formulas of compared slip surfaces.

\begin{tabular}{lc}
\hline $\begin{array}{l}\text { Curves } \\
\text { for slip surface }\end{array}$ & Slip \\
\hline ParaGoel & $y=\left(\left(0.989 \cdot \tan ^{2}((\pi / 4)+(\varphi / 2))\right) / H\right) \cdot$ \\
ParaNew & $\left.x^{2}+\tan ^{2}(\pi / 4)+(\varphi / 2)\right) \cdot x$ \\
ExpTsagareli & Equation $(1)$ \\
ExpNew & $y=(3.6 \cdot \varphi+0.5)^{x}-1$ \\
\hline
\end{tabular}

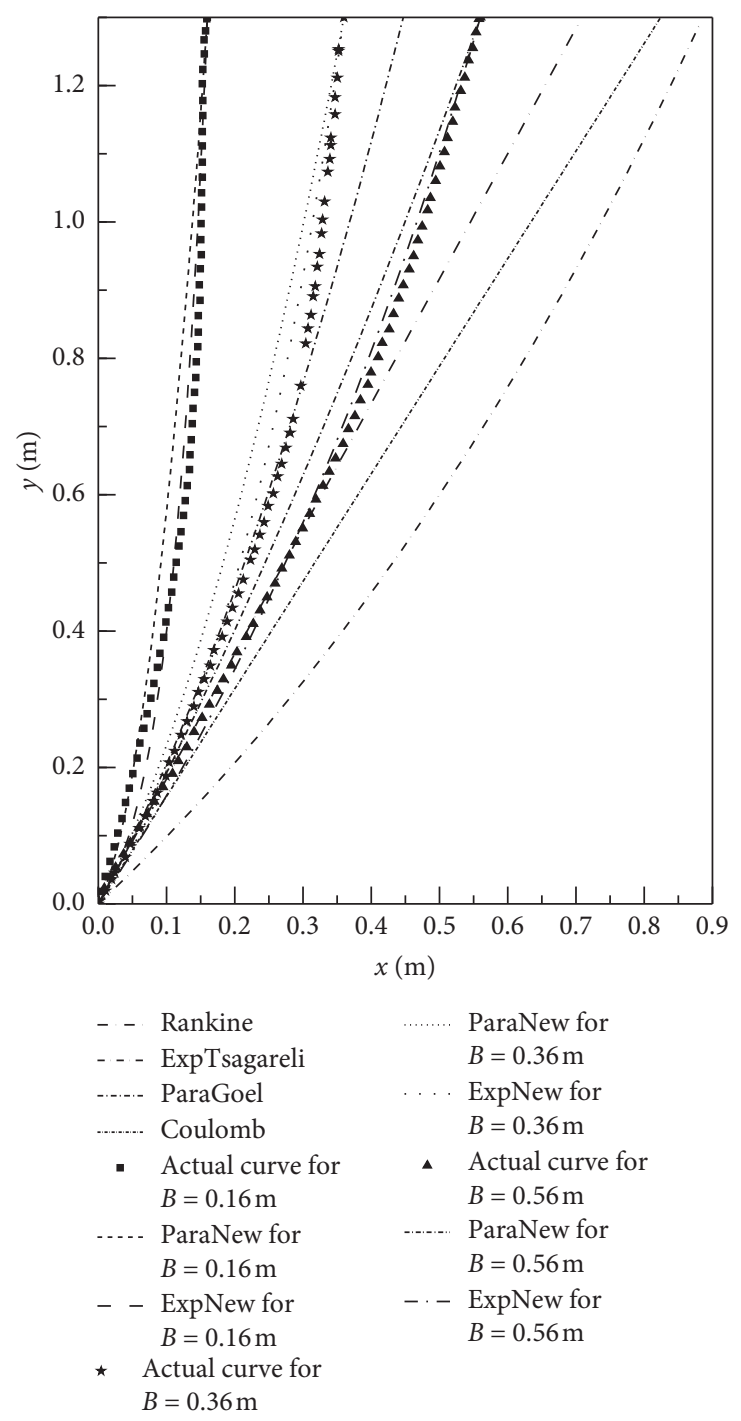

Figure 2: Performance of various equations of the slip surface.

$$
L(y)=\frac{C \cdot \ln ((C+y) / C)}{\ln (1.8 \varphi+0.9 \pi+0.5)},
$$

and the angle $\alpha(y)$ between the slip surface at a given height $y$ and horizontal direction can be written as

$$
\begin{aligned}
\alpha(y)= & \tan ^{-1}\left[(1.8 \varphi+0.9 \pi+0.5)^{(\ln ((C+y) / C)) /(\ln (1.8 \varphi+0.9 \pi+0.5))}\right. \\
& \cdot \ln (1.8 \varphi+0.9 \pi+0.5)]
\end{aligned}
$$

\section{Stress at Wall and Slip Surface in the Critical State}

Handy [11] believed that due to the presence of wall-soil friction, the direction of the major principal stress acting on the horizontal backfill layer is deviated from the original vertical direction. However, the distribution of the principal stress rotation angle cannot be accurately figured out. Over the years, the shapes of circular [15], parabolic [7, 17], catenary [11], straight line [18], etc. have been used to represent 
the distribution of principal stress. The method of minor principal stress trajectory needs to make assumption on the stress state of the backfill over the entire horizontal strip. It also requires that the major and minor principal stress values on the same horizontal plane are constants, which is not always achievable.

It is widely accepted that without wall-soil friction, the major and minor principal stress at the same level are constants. Thus, the relationship between the principal stresses at each point on the horizontal strip is related to the friction on the boundaries of wall-backfill interface and the slip surface when in the limit equilibrium state. If the width of the sliding body at a given height is relatively large, it is reasonable to assume that the principal stress along the horizontal strip is constant. That is because the friction is now a minor boundary condition due to the limited actuating range of wall-soil friction and slip surface friction.

However, for a narrow backfill, the width of the sliding body is relatively small; thus, it may be bold to assume that the principal stresses of all the internal points of the horizontal strip are constants. Therefore, this paper only makes assumption on the principal stresses of the backfill in the slip surface and at the wall-soil interface when in the limit equilibrium state. Specifically, it is assumed that at a given depth, the minor principal stress at the wall-soil interface is the same with that on the slip surface. The Mohr-Coulomb criterion [25] is also accepted here to determine the limit equilibrium state. Therefore, according to the theory of the Mohr stress circle [26], the stress at two points can be obtained as shown in Figure 3.

Based on Figure 3, the relation of major principal stress on the slip surface and at the wall can be written as

$$
\frac{\sigma_{1}(s)}{\sigma_{1}(w)}=\frac{(1+\sin \varphi)(1-\sin \delta)}{(1-\sin \varphi)(1+\sin \delta)}
$$

and the normal stress on the slip surface and the normal stress on the wall-soil interface can be obtained as (7) and (8), respectively:

$$
\begin{aligned}
\sigma_{\mathrm{ns}} & =(1-\sin \varphi) \sigma_{1}(s), \\
\sigma_{\mathrm{hw}} & =\sigma_{\mathrm{nw}}=(1-\sin \delta) \sigma_{1}(w) .
\end{aligned}
$$

Therefore, the ratio of normal stress on the slip surface to normal stress on the wall-soil interface can be written as

$$
\lambda=\frac{\sigma_{\mathrm{ns}}}{\sigma_{\mathrm{hw}}}=\frac{1+\sin \varphi}{1+\sin \delta} .
$$

\section{Establishment of Equilibrium Equation}

The following Figure 4 is the free body diagram of the differential horizontal strip at a certain height $y$.

From Figure 4, the normal forces acting on the wallbackfill interface and the slip surface can be calculated as (10) and (11), respectively:

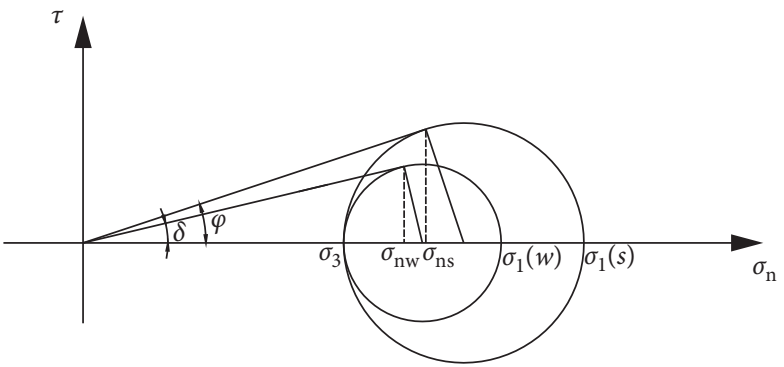

FIgURE 3: 2D Mohr stress circles for the wall-soil interface and its horizontally corresponding slip surface.

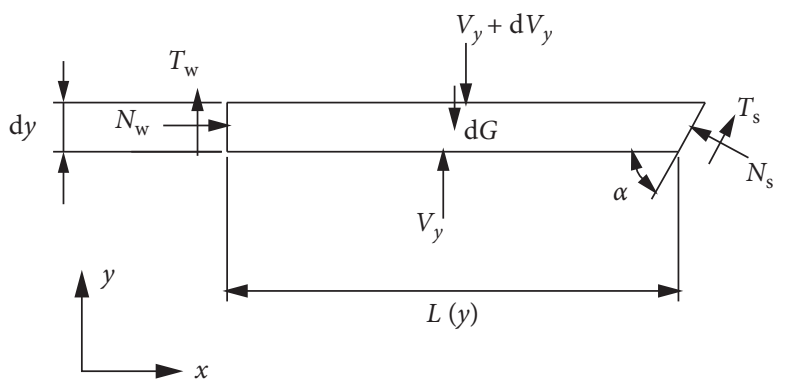

FIGURE 4: Force analysis of the differential horizontal backfill strip.

$$
\begin{aligned}
& N_{\mathrm{w}}=\sigma_{\mathrm{hw}} \mathrm{d} y, \\
& N_{\mathrm{s}}=\sigma_{\mathrm{ns}} \mathrm{d} y \csc \alpha .
\end{aligned}
$$

The weight of the differential flat backfill strip is

$$
\mathrm{d} G=\gamma \frac{\mathrm{d} y \mathrm{~d} y}{2 \tan \alpha(y)}+\gamma L(y) \mathrm{d} y,
$$

where $\gamma$ is the unit weight of backfill. And the differential vertical force on upper level of the differential flat strip is

$$
\mathrm{d} V_{y}=\overline{\sigma_{y}} \mathrm{~d} y \cot \alpha(y)+\mathrm{d} \overline{\sigma_{y}}[L(y)+\mathrm{d} y \cot \alpha(y)] .
$$

It is generally assumed that the wall-backfill interface and the slip surface are in the limit equilibrium state defined by Mohr-Coulomb criteria and the friction coefficient is the tangent of the corresponding friction angle. Therefore, shear force acting on the wall-backfill interface and the slip surface can be given as (14) and (15), respectively:

$$
\begin{aligned}
T_{\mathrm{w}} & =\sigma_{\mathrm{hw}} \tan \delta \mathrm{d} y, \\
T_{\mathrm{s}} & =\sigma_{\mathrm{ns}} \tan \varphi \csc \alpha \mathrm{d} y .
\end{aligned}
$$

Then, the vertical static equilibrium equation of the differential horizontal backfill strip can be obtained as follows:

$$
\frac{\mathrm{d} \overline{\sigma_{y}}}{\mathrm{~d} y}+\frac{\overline{\sigma_{y}} \cot \alpha}{L(y)}=-\gamma+\frac{\sigma_{\mathrm{hW}} \tan \delta+\lambda \sigma_{\mathrm{hW}}[\tan \varphi+\cot \alpha(y)]}{L(y)} .
$$

Substituting (9) into (16), then (16) can be written as follows: 


$$
\frac{\mathrm{d} \overline{\sigma_{y}}}{\mathrm{~d} y}+\overline{\sigma_{y}}\left[\frac{\cot \alpha}{L(y)}-\frac{K \tan \delta+K((1+\sin \varphi) /(1+\sin \delta))[\tan \varphi+\cot \alpha(y)]}{L(y)}\right]+\gamma=0
$$

\section{Estimation of Active Earth Pressure Coefficient}

The lateral earth pressure coefficient $K$ is usually defined as

$$
K=\frac{\sigma_{\mathrm{hw}}}{\overline{\sigma_{y}}} .
$$

The commonly used formulas for calculating earth pressure are for the linear slip surface. Moreover, the limited backfill width is not considered, which means that the key variable of the backfill width is neglected. Therefore, those formulas cannot be directly used and compared for earth pressure calculation in the case of narrow backfill, but the expression of $K$ is universal and can be used for calculation in the narrow backfill. In fact, Singh et al. [27] examined the role of $\varphi$ and $K$ in earth pressure calculations and highlighted the importance of $K$. To estimate a suitable $K$, Table 4 lists some most widely used choices for $K$.

\section{Calculation of Earth Pressure}

The expressions of $L(y)$ and $\alpha(y)$ obtained from the exponential slip surface consist of transcendental functions, which means that a simple analytical solution of the differential equation cannot be obtained or the obtained expression is too complicated to be applied in practice. Thus, the method of finite difference with Richardson extrapolation [29] was used to solve (17), and the calculated results are shown in Figures 5-7.

The results indicated that the value of $K$ has an important influence on earth pressure distribution, which confirms the research of Singh et al. [27]: $K$ is a key parameter. Since it is aimed at the backfill of large aspect ratio, the distribution of earth pressure along the dimensionless depth is inevitably different from that of the width-free backfill.

It can be seen from these figures that in the case of $W=0.16 \mathrm{~m}$, when the dimensionless depth is less than 0.68 (actual depth is $5.53 \mathrm{~W}$ ), the calculated earth pressure increases with increasing $K$; when the dimensionless depth is greater than 0.68 , the calculated earth pressure decreases with increasing $K$. When the width is $0.36 \mathrm{~m}$, the critical dimensionless depth is about 0.78 (actual depth is $2.82 \mathrm{~W}$ ); when the width is $0.56 \mathrm{~m}$, the critical dimensionless depth is about 0.84 (actual depth is $1.95 \mathrm{~W}$ ).

There seems to be a critical $K$ value, and only beyond this critical value, the dimensionless earth pressure will gradually converge to zero at the bottom. If a small value of $K$ is used, the calculated earth pressure is in good agreement with the test data when the depth is shallow; however, the dimensionless earth pressure obtained will not converge to zero at the bottom. Once the $K$ value exceeds a certain limit, the dimensionless earth pressure will tend to zero at the bottom.
Specifically, when the aspect ratio of the backfill is not pretty large $(W=0.36 \mathrm{~m}, 0.56 \mathrm{~m})$ and the buried depth is shallow $(h / H \leq 0.6)$, the results using $K$ from Paik and Salgado [15] or Khosravi et al. [4] are closest to the experimental data. When in deep $(h / H \geq 0.6)$, the calculated result using Jaky's $K$ [28] value is closest to experimental results. For the case of $W=0.16$, all $K$ used in this paper cannot yield a good result.

\section{Discussion}

7.1. Selection of Slip Surface Shape. The linear slip surface proposed by Rankine [5] and Coulomb [6] is based on the failure criterion, concerning only the backfill property $\varphi$ and the wall-soil friction angle $\delta$; the slip surface of Tsagareli [8] only concerns the height at which the slip surface intersects the wall, yet the aspect ratio is omitted. The parabola equation of Goel and Patra [7] considers the reduction of the width at the top of the slip body, but how to choose the reduction factor is not clear. Therefore, these slip surface equations do not adequately consider the geometric layout of the backfill.

For the most commonly used linear slip surface of Rankine [5] (with an angle of $(\pi / 4+\varphi / 2)$ from horizontal direction), the minimum width requirement for the filling body is $\cot (\pi / 4+\varphi / 2)^{*} H$. The minimum required width is $0.545 \mathrm{H}$ if the internal friction angle $32.8^{\circ}$ is used, while the width of the filling body discussed does not exceed $0.431 \mathrm{H}$, that is, to say at least an additional $26.57 \%$ of the width is required to achieve this requirement. The slip surfaces of Coulomb [6] and Tsagareli [8] are also outside the actual backfill body. It can be concluded that the geometry of the actual backfill body should be evaluated before choosing an existing slip surface model. Since the linear slip surface of Rankine [5] is most commonly used, $\cot (\pi / 4+\varphi / 2)^{*} H$ can be used as a critical aspect ratio for defining a confined backfill space. If the width of backfill is smaller than this value, the backfill is considered a confined backfill; and, if the width of backfill is larger than this value, the backfill is considered a general backfill. The slip surface formed when the confined cohesionless backfill is in the active state should be a function of the backfill geometry, the backfill property, and the wall-soil friction angle.

In summary, the slip surface calculation method of this paper is for the confined backfill $\left(W<\cot (\pi / 4+\varphi / 2)^{*} H\right)$, and the obtained slip surface will change as the geometry condition of backfill changes. Thus, it is more adaptable to certain projects and only geometric measurements and friction angle experiments are required.

7.2. Calculation of Earth Pressure. There are several calculation methods for the earth pressure based on a curved slip surface, and most of them are complicated, especially for the confined backfill. In this paper, the conservative assumptions 
TABLE 4: Various $K$ values in this paper from widely used formulas.

\begin{tabular}{lcc}
\hline Method & Expression of $K$ & $K$ values in the case of $\varphi=32.8^{\circ}, \delta=22^{\circ}$ \\
\hline Coulomb [6] & $\cos ^{2} \varphi /\left(\cos \delta \cdot(1+\sqrt{(\sin (\delta+\varphi) \cdot \sin \varphi) / \cos \delta})^{2}\right)$ & 0.267 \\
Rankine [5] & $(1-\sin \varphi) /(1+\sin \varphi)$ & 0.297 \\
Handy [11] & $1.06 \cdot\left[\cos ^{2} \theta_{\mathrm{w}}+\left(\sigma_{3}(s) / \sigma_{1}(s)\right) \sin ^{2} \theta_{\mathrm{w}}\right]$ & 0.324 \\
Paik and Salgado [15] & $\left(3\left(N \cos ^{2} \theta_{\mathrm{w}}+\sin ^{2} \theta_{\mathrm{w}}\right)\right) /\left(3 N-(N-1) \cos ^{2} \theta_{\mathrm{w}}\right)$ & 0.325 \\
Khosravi et al. [4] & $(1-\cos [\arcsin (\sin \delta / \sin \varphi)-\delta] \sin \varphi) /(1+$ & 0.331 \\
Jaky [28] & $\cos [\arcsin (\sin \delta / \sin \varphi)-\delta] \sin \varphi)$ & 0.458 \\
For test & $1-\sin (\varphi)$ & 0.375 \\
For test & $\sin (\delta)$ & 0.542 \\
\hline
\end{tabular}

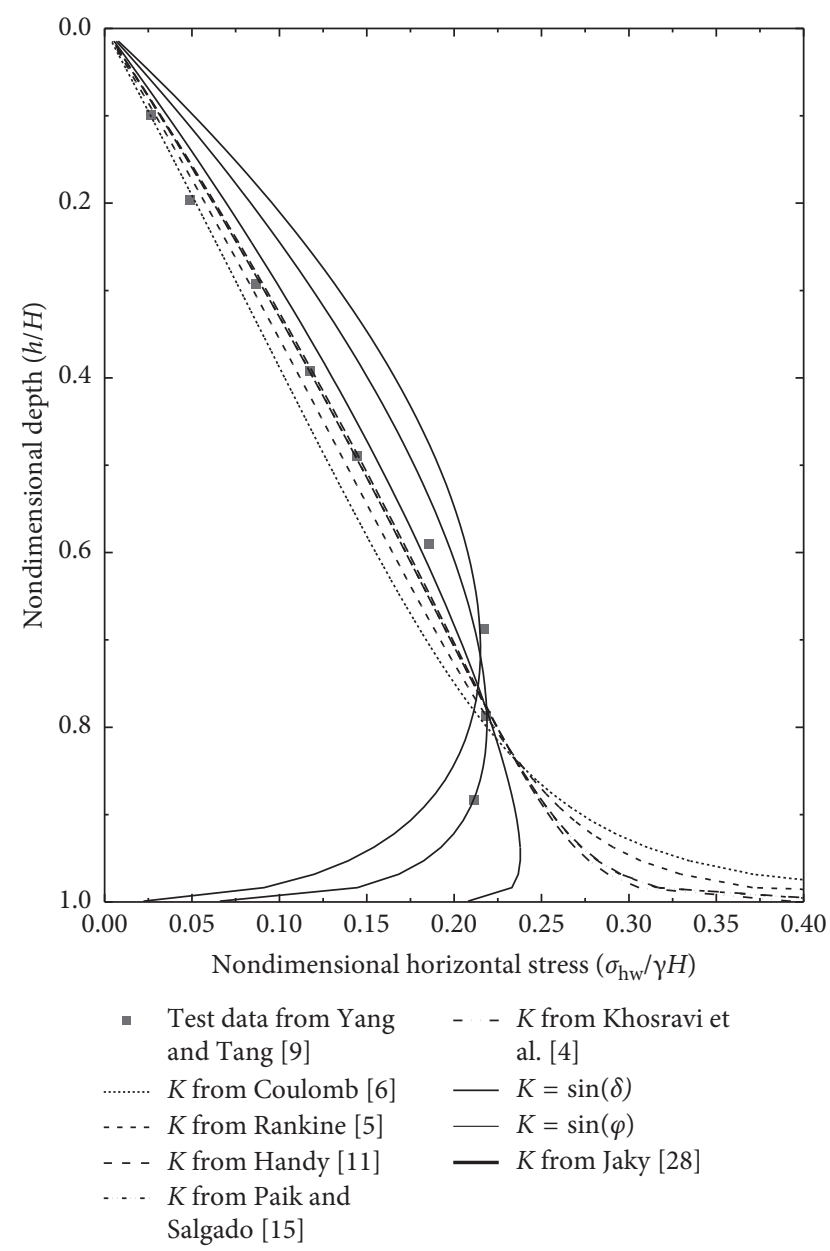

Figure 5: Measured and calculated dimensionless earth pressure versus $h / H$, for width $=0.56 \mathrm{~m}$.

are used to analyse the earth pressure state on the slip surface and the wall-soil interface. And, the used $K$ values in this manuscript can be divided into three categories: the first kind of $K$ is based on analysis of infinite backfill subject to a certain ideal constitutive model, such as Rankine's and Coulomb's; the second kind of $K$ is based on the assumption of boundary condition at the backfill-wall interface, such as Handy's, Paik's, and Khosravi's; and the third kind is to be assessed, such as Jaky's $K, \sin (\varphi)$, and $\sin (\delta)$. The first kind of $K$ is corresponding to the ideal backfill; the second kind of $K$ assumes a stress boundary condition at the wall-backfill

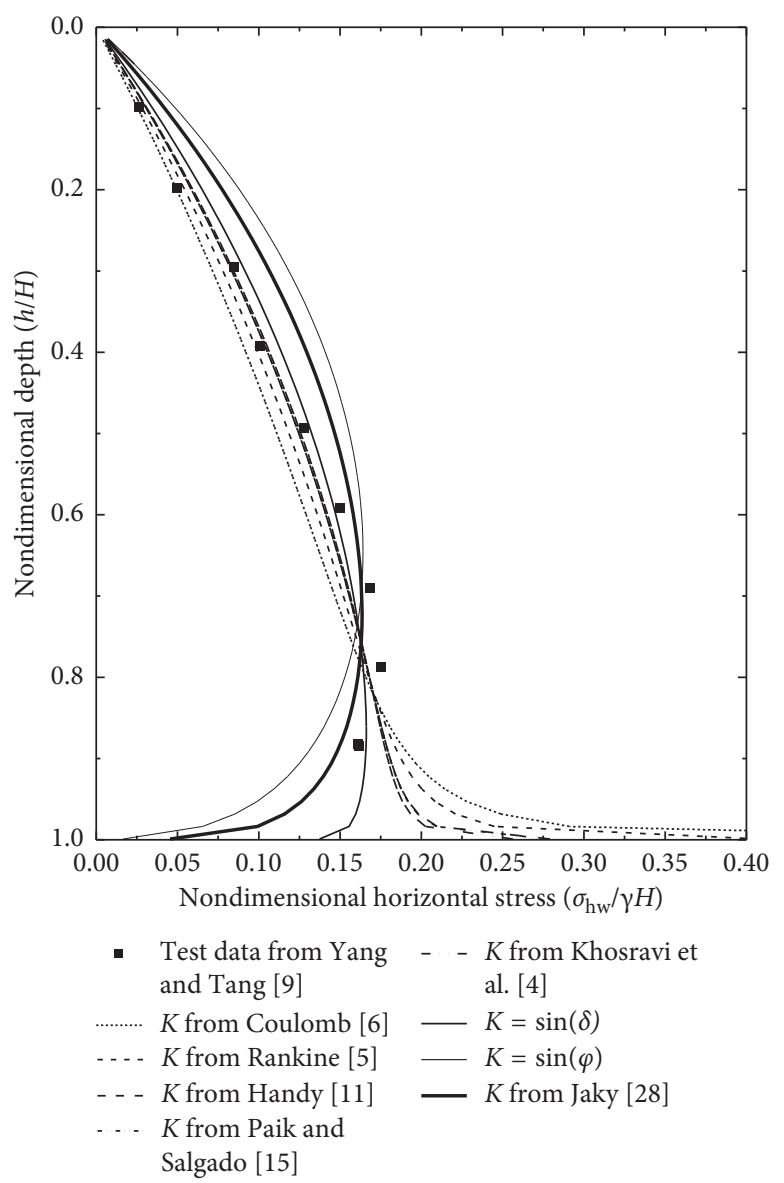

FIGURE 6: Measured and calculated dimensionless earth pressure versus $h / H$, for width $=0.36 \mathrm{~m}$.

interface expressed in the Mohr circle. Any assumption can only be used in its own scope of application. So, the piecewise $K$ values mean piecewise applicable condition along the depth. The results showed that when the depth is shallow, the $K$ values of Handy, Paik, and Khosravi are workable, which means that the assumption of these three $K$ values is workable when the depth is shallow. However, when the depth is large $(h / W>\tan (\pi / 4+\varphi / 2))$, these assumptions no longer conform to the actual case. So, a larger value of Jaky's $K$ which is corresponding to static condition was used to describe the lateral pressure.

For the test material, the boundary aspect ratio is 1.83 $\left(\tan (\pi / 4+\varphi / 2)\right.$ when $\left.\varphi=32.8^{\circ}\right)$. When the width of test 


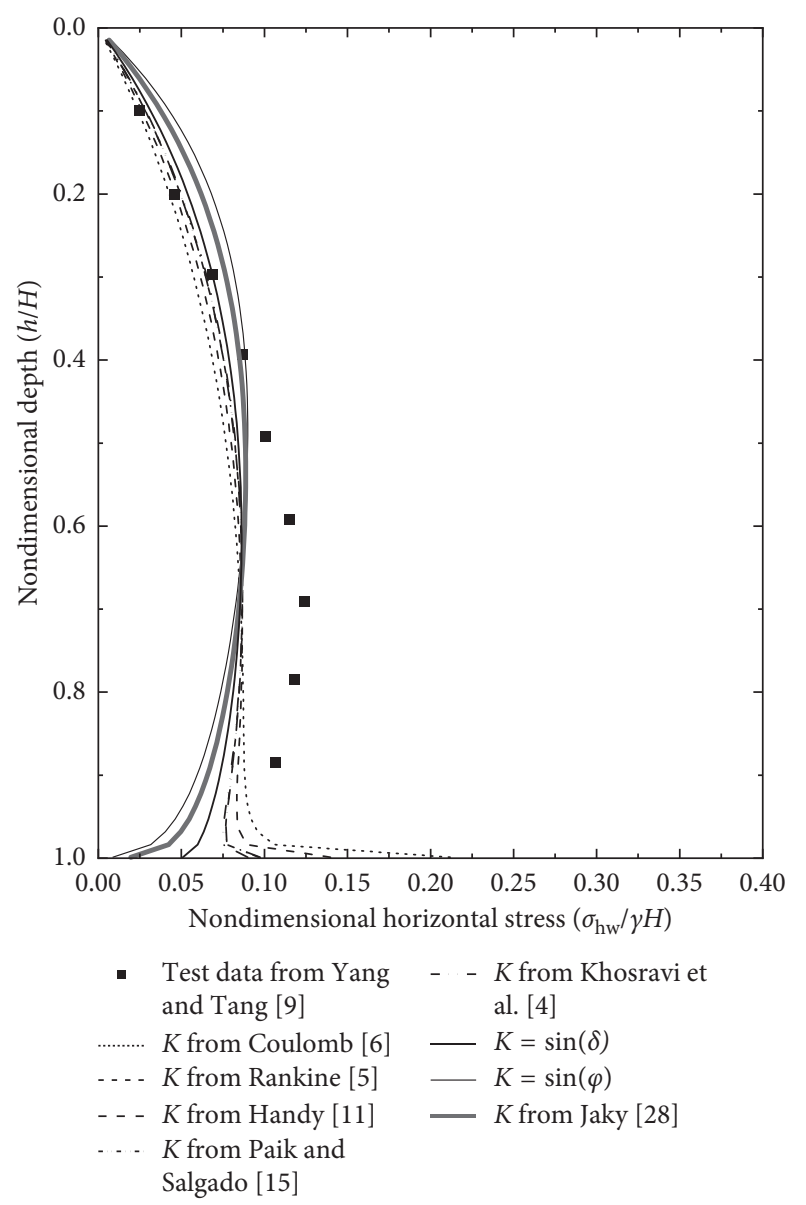

FIGURE 7: Measured and calculated dimensionless earth pressure versus $h / H$, for width $=0.16 \mathrm{~m}$.

backfill is $0.56 \mathrm{~m}$, the critical depth (the depth related to the boundary aspect ratio) is $1.027 \mathrm{~m}$ with a dimensionless depth of 0.79 . When the width of the test backfill is $0.36 \mathrm{~m}$, the critical depth is $0.659 \mathrm{~m}$ with a dimensionless depth of 0.507 . When the width of the test backfill is $0.16 \mathrm{~m}$, the critical depth is $0.293 \mathrm{~m}$ with a dimensionless depth of 0.23 . We may anticipate some incongruity between the second kind of $K$ and the test data when the depth transcends the critical value.

Then, in Figure 5, we can clearly see that when the dimensionless depth is less than 0.7 , the second kind of $K$ is most suitable, and all these three $K$ values showed a good agreement with the test data. In Figure 6, these three $K$ values also showed a good performance, but the critical dimensionless depth is 0.5. In Figure 7, these three $K$ values behave well when the dimensionless depth is less than about 0.25 . So, the critical depths in Figures 5-7 showed good agreement with the anticipated critical depths. And, when the depth is larger than the critical depth, the Jaky's $K$ which is corresponding to static condition behaves better, as can be seen in Figures 5 and 6. But for depth with much larger aspect ratio, the Jaky's $K$ also underestimates the earth pressure, as can be seen in Figure 7 .

But in general physical test, the width of the backfill is enough (at least no less than $H / \tan (\pi / 4+\varphi / 2)$ ), so this phenomenon is neglected. So, this is exactly why various $K$ values were used here.

And for the narrow backfill, the $K$ value is different from that in the shallow region. Even if the backfill is in the active state, the lateral stress is more similar to static stress condition. However, the calculation result of the deeper backfill is too small when the backfill has a large aspect ratio (width $=0.16 \mathrm{~m}$ and the ratio of height to width is 8.125), and the reasons for this difference may be explained as follows:

(1) Possible measurement errors [30].

(2) In this case, the distance between the wall-soil interface and the slip surface is very small, and the relative change along the buried depth is not large. The shear stress between the horizontal layers probably should not be ignored because the angle of the slip surface has a greater impact on the earth pressure if the interlaminar shear stress is ignored, as is mentioned by Liu et al. [31].

The results shown in Figure 5 indicated that the proposed method overestimates the disturbance caused by the wall-soil friction on the horizontal soil stress state, which leads to the underestimation of the earth pressure. In contrast, the calculation methods of Rankine and Coulomb, which do not consider the arching effect, greatly overestimate the calculation of earth pressure. To what degree the arching effect is considered is reflected by the Mohr stress circle at the wall-soil interface. When the arching effect is not considered at all, $\sigma_{\mathrm{hw}}$ is the same as $\sigma_{1}(w)$. However, $\sigma_{\mathrm{hw}}$ in Figure 3 equals $(1-\sin \delta) \sigma_{1}(w)$. Therefore, the relationship between $\sigma_{\mathrm{hw}}$ and the major principal stress at this time (shown in Figure 3) is no longer suitable for the wall-soil interface, and a more suitable relationship needs further study.

To give a feasible solution for practice, the authors observed that under the large aspect ratio $(H / W>8)$ with a width of $0.16 \mathrm{~m}$, both the methods of Rankine [5] and Coulomb [6] show a large degree deviation. For this reason, the author tried using a method of "equivalent width" to adapt the method of Rankine [5] and Coulomb [6]; that is, taking the linearly distributed earth pressure solution and making the following adaption:

$$
\sigma_{\mathrm{hw}}=K_{a} \cdot \frac{L(y)}{W} \cdot \gamma h
$$

So, the adapted solutions of Coulomb and Rankine become (20) and (21), respectively:

$$
\sigma_{\mathrm{hw}}=\frac{\cos ^{2} \varphi}{\cos \delta(1+\sqrt{(\sin (\delta+\varphi) \sin \varphi) / \cos \delta})^{2}} \frac{L(y)}{W} \gamma h,
$$

$$
\sigma_{\mathrm{hw}}=\frac{1-\sin \varphi}{1+\sin \varphi} \frac{L(y)}{W} \gamma h .
$$

The results are shown in Figure 8.

This method is only an attempt. Figure 8 shows that the results agree well with the experimental data when $W=0.16 \mathrm{~m}$ with an aspect ratio of 8.125. However, the calculated earth 


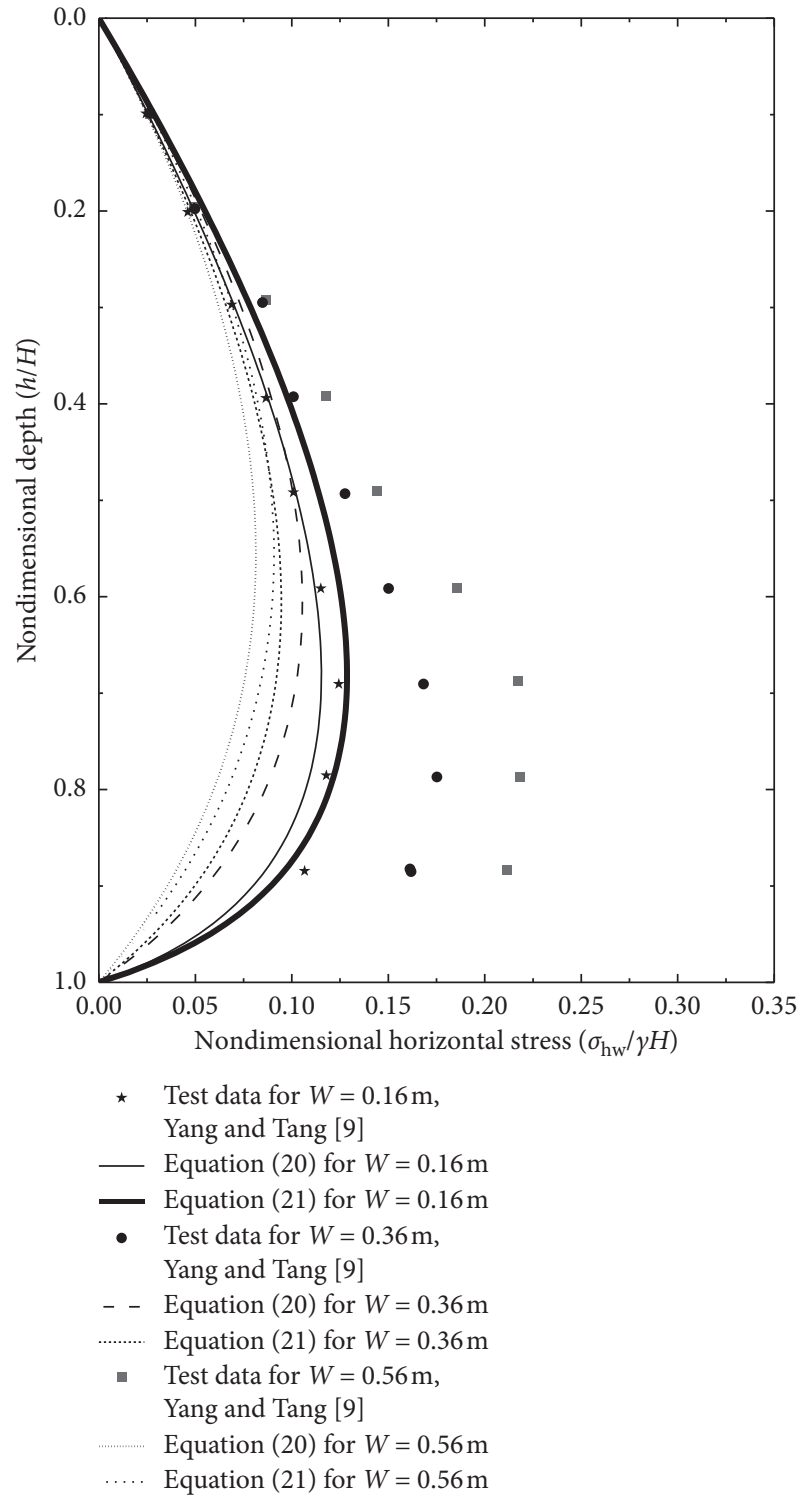

FIGURE 8: Calculated results of the attempted method.

pressure is especially small when the width is $0.36 \mathrm{~m}$ or $0.56 \mathrm{~m}$. Therefore, the earth pressure calculation method tried here is only feasible under a very large aspect ratio and can be used as an engineering trial calculation. The applicability needs to be examined with the actual measured data.

\section{Conclusions}

In this paper, the cohesionless backfill with limited width is studied to explore a suitable equation for the slip surface and a calculation method for the active earth pressure under the translation mode of the vertical rough rigid retaining wall. The following conclusions are obtained:

(1) The anew proposed exponential curve is closer to the actual slip surface than the usual formulas of parabolic curve, Tsagareli's [8] exponential curve, and linear curve. When using this formula to characterize the geometry of the slip surface, the height and width of the backfill as well as the internal friction angle of the backfill need to be provided to obtain the key parameter $C$. And, $C$ should be obtained individually according to the specific engineering data.

(2) It is found that the selection of the $K$ value of the lateral earth pressure coefficient has a great influence on the active earth pressure. It is recommended choosing $K=$ $1-\sin (\varphi)$ or using the value of $K$ from Paik and Salgado [15] or Khosravi et al. [4]. Under the larger aspect ratio $(H / W=8.125)$, it is recommended to try the improved methods of Rankine and Coulomb in the "Discussion" section. The method proposed in this paper is suitable for the cohesionless backfill with large aspect ratio, known as the narrow backfill and confined backfill. If the material properties and geometric properties of the backfill meet the above requirements, the method proposed in this paper can be used; otherwise other methods should be referred to.

\section{Notations}

C: Constant used in exponential slip surface

G: Gravity

$H$ : Total height of backfill

$h$ : $\quad$ Buried depth from top of backfill

$K$ : Lateral earth pressure coefficient

$L$ : Width of sliding body at a given height

$N$ : The value of $\sigma_{1} / \sigma_{3}$

$N_{\mathrm{w}}$ : Normal stress at wall

$N_{s}$ : Normal stress at slip surface

$T_{\mathrm{w}}$ : Tangential stress at wall

$T_{\mathrm{s}}$ : Tangential stress at slip surface

$V_{y}$ : Vertical force on horizontal backfill strip at a given height of $y$

$W$ : Width of backfill

$y$ : Height of horizontal backfill strip

$\alpha: \quad$ Inclination of horizontal backfill strip

$\gamma$ : Unit weight of backfill

$\delta$ : Friction angle of wall-backfill interface

$\theta_{\mathrm{w}}$ : Rotation angle of major principal stress at the wall

$\lambda$ : $\quad$ Ratio of $\sigma_{\mathrm{ns}}$ to $\sigma_{\mathrm{hw}}$

$\sigma_{\mathrm{hw}}$ : Horizontal stress at wall

$\sigma_{\mathrm{ns}}:$ Normal stress at slip surface

$\sigma_{\mathrm{nw}}:$ Normal stress at wall

$\frac{\mathrm{n}}{\sigma_{y}}:$ Average vertical stress on horizontal backfill at a given height of $y$

$\sigma_{1}: \quad$ Major principal stress

$\sigma_{3}$ : Minor principal stress

$\varphi$ : Internal friction angle of backfill.

\section{Data Availability}

The data used to support the findings of this study are available from the corresponding author upon request.

\section{Conflicts of Interest}

There are no conflicts of interest regarding the publication of this paper. 


\section{Acknowledgments}

This work was financially supported by the National Natural Science Foundation of China (Grant No. 51674012 and 51574013).

\section{References}

[1] L. Li, "Generalized solution for mining backfill design," International Journal of Geomechanics, vol. 14, no. 3, Article ID 04014006, 2013.

[2] W. A. Take and A. J. Valsangkar, "Earth pressures on unyielding retaining walls of narrow backfill width," Canadian Geotechnical Journal, vol. 38, no. 6, pp. 1220-1230, 2001.

[3] C. H. Ting, S. K. Shukla, and N. Sivakugan, "Arching in soils applied to inclined mine stopes," International Journal of Geomechanics, vol. 11, no. 1, pp. 29-35, 2011.

[4] M. H. Khosravi, T. Pipatpongsa, and J. Takemura, "Theoretical analysis of earth pressure against rigid retaining walls under translation mode," Soils and Foundations, vol. 56, no. 4, pp. 664-675, 2016.

[5] W. M. Rankine, "On the stability of loose earth," Philosophical Transactions of the Royal Society of London, vol. 147, pp. 9-27, 1857.

[6] C. A. Coulomb, Essai sur une application des règles de maximis et minimis à quelques problèmes de statique, relatifs à l'architecture, Vol. 7, Memoirs Academie Royal Pres. Division. Sav, Paris, France, 1776.

[7] S. Goel and N. R. Patra, "Effect of arching on active earth pressure for rigid retaining walls considering translation mode," International Journal of Geomechanics, vol. 8, no. 2, pp. 123-133, 2008.

[8] Z. V. Tsagareli, "Experimental investigation of the pressure of a loose medium on retaining walls with a vertical back face and horizontal backfill surface," Soil Mechanics and Foundation Engineering, vol. 2, no. 4, pp. 197-200, 1965.

[9] M. Yang and X. Tang, "Rigid retaining walls with narrow cohesionless backfills under various wall movement modes," International Journal of Geomechanics, vol. 17, no. 11, Article ID 04017098, 2017.

[10] S. Frydman and I. Keissar, "Earth pressure on retaining walls near rock faces," Journal of Geotechnical Engineering, vol. 113, no. 6, pp. 586-599, 1987.

[11] R. L. Handy, “The arch in soil arching," Journal of Geotechnical Engineering, vol. 111, no. 3, pp. 302-318, 1985.

[12] H. K. Kerlyn, Mechanics of Granular Structures, T. W. Chen, Ed., People's Communication Publishing House, Beijing, China, 1977.

[13] M. H. Khosravi, T. Pipatpongsa, and J. Takemura, "Experimental analysis of earth pressure against rigid retaining walls under translation mode," Géotechnique, vol. 63, no. 12, pp. 1020-1028, 2013.

[14] Y.-Z. Wang, "Distribution of earth pressure on a retaining wall," Géotechnique, vol. 50, no. 1, pp. 83-88, 2000.

[15] K. H. Paik and R. Salgado, "Estimation of active earth pressure against rigid retaining walls considering arching effects," Géotechnique, vol. 53, no. 7, pp. 643-653, 2003.

[16] P. Rao, Q. Chen, Y. Zhou, S. Nimbalkar, and G. Chiaro, "Determination of active earth pressure on rigid retaining wall considering arching effect in cohesive backfill soil," International Journal of Geomechanics, vol. 16, no. 3, Article ID 04015082, 2016.

[17] Y. T. Zhou, Q. S. Chen, F. Q. Chen, X. H. Xue, and S. Basack, "Active earth pressure on translating rigid retaining structures considering soil arching effect," European Journal of Environmental and Civil Engineering, vol. 22, no. 8, pp. 910-926, 2018.

[18] J. P. Li and M. Wang, "Simplified method for calculating active earth pressure on rigid retaining walls considering the arching effect under translational mode," International Journal of Geomechanics, vol. 14, no. 2, pp. 282-290, 2013.

[19] J. Chen, M. Li, and J. Wang, "Active earth pressure against rigid retaining walls subjected to confined cohesionless soil," International Journal of Geomechanics, vol. 17, no. 6, Article ID 06016041, 2017.

[20] C.-C. Fan and Y.-S. Fang, "Numerical solution of active earth pressures on rigid retaining walls built near rock faces," Computers and Geotechnics, vol. 37, no. 7-8, pp. 1023-1029, 2010.

[21] S. Xu, A. Shamsabadi, and E. Taciroglu, "Evaluation of active and passive seismic earth pressures considering internal friction and cohesion," Soil Dynamics and Earthquake Engineering, vol. 70, pp. 30-47, 2015.

[22] S. Xu, K. K. P. M. Kannangara, and E. Taciroglu, "Analysis of the stress distribution across a retaining wall backfill," Comput. Geotech, vol. 103, pp. 13-25, 2018.

[23] Y. Xie and B. Leshchinsky, "Active earth pressures from a logspiral slip surface with arching effects," Géotechnique Letters, vol. 6, no. 2, pp. 149-155, 2016.

[24] M. H. Khosravi, A. R. Kargar, and M. Amini, "Active earth pressures for non-planar to planar slip surfaces considering soil arching," International Journal of Geotechnical Engineering, vol. 12, pp. 1-10, 2018.

[25] J. F. Labuz and A. Zang, "Mohr-coulomb failure criterion," Rock Mechanics and Rock Engineering, vol. 45, no. 6, pp. 975-979, 2012.

[26] O. Mohr, "Uber die Darstellung des Spannungszustandes und des Deformationszustandes eines Korperelementes und uber die Anwendung derselben in der Festigkeitslehre," Der Civlingenieur, vol. 28, pp. 113-156, 1882.

[27] S. Singh, N. Sivakugan, and S. K. Shukla, "Can soil arching be insensitive to $\phi$ ?," International Journal of Geomechanics, vol. 10, no. 3, pp. 124-128, 2010.

[28] J. Jaky, "Pressure in silos," in Proceedings of the Second International Conference on Soil Mechanics and Foundation Engineering, vol. 1, pp. 103-107, Rotterdam, Netherlands, June 1948.

[29] L. F. Richardson, "The approximate arithmetical solution by finite differences of physical problems involving differential equations, with an application to the stresses in a masonry dam," Philosophical Transactions of the Royal Society A: Mathematical, Physical and Engineering Sciences, vol. 210, no. 459-470, pp. 307-357, 1911.

[30] M. Yang, "Reply to the discussion on "Calculation of earth pressure for limited soils with curved slip surface"," Rock and Soil Mechanics, vol. 39, no. 1, pp. 395-396, 2018, in Chinese.

[31] Z. Liu, J. Chen, and D. Li, "Calculation of active earth pressure against rigid retaining wall considering shear stress," Rock and Soil Mechanics, vol. 37, no. 9, pp. 2443-2450, 2016, in Chinese. 


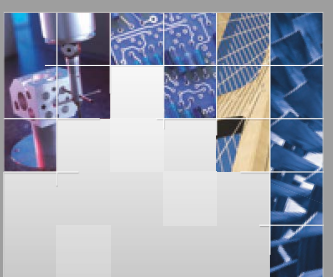

\section{Enfincering}
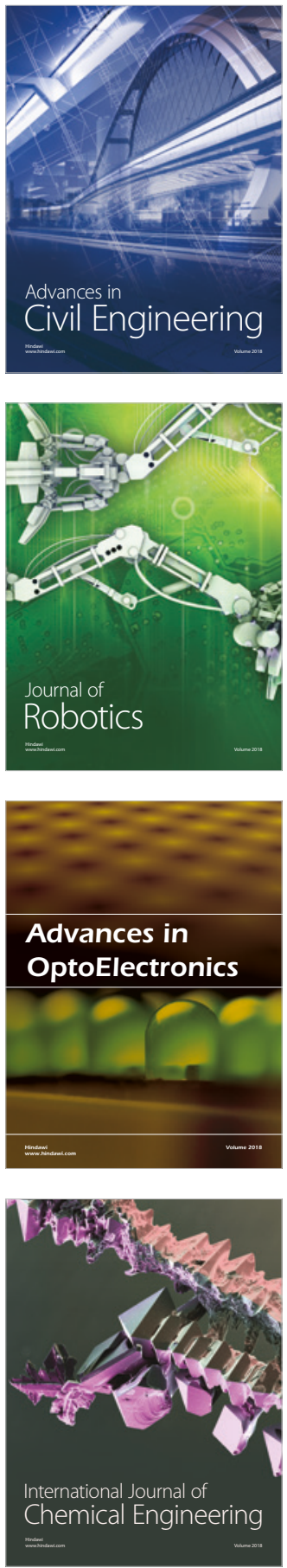

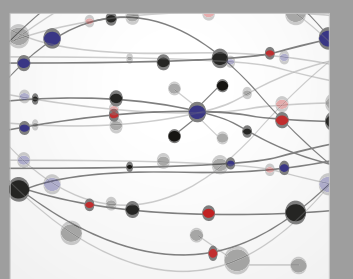

\section{Rotating \\ Machinery}

The Scientific World Journal

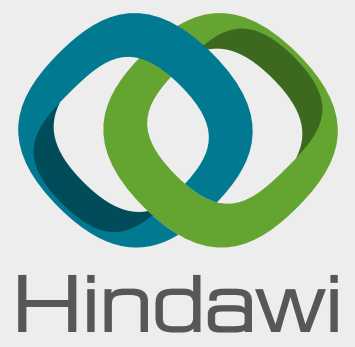

Submit your manuscripts at

www.hindawi.com
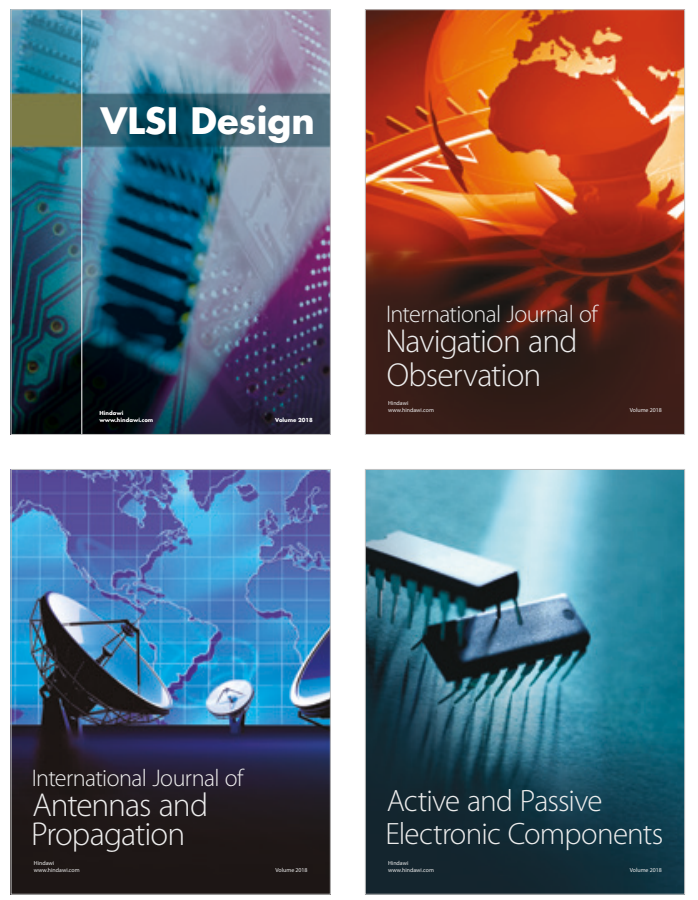
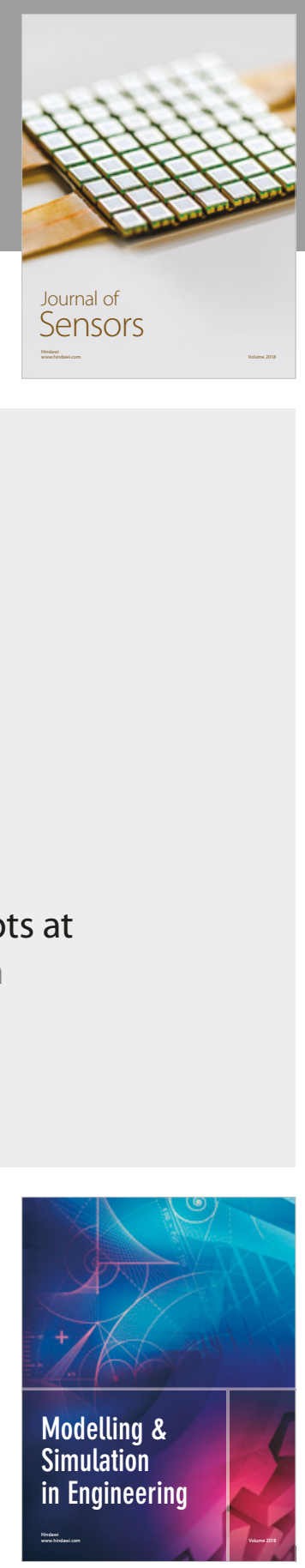

\section{Advances \\ Multimedia}
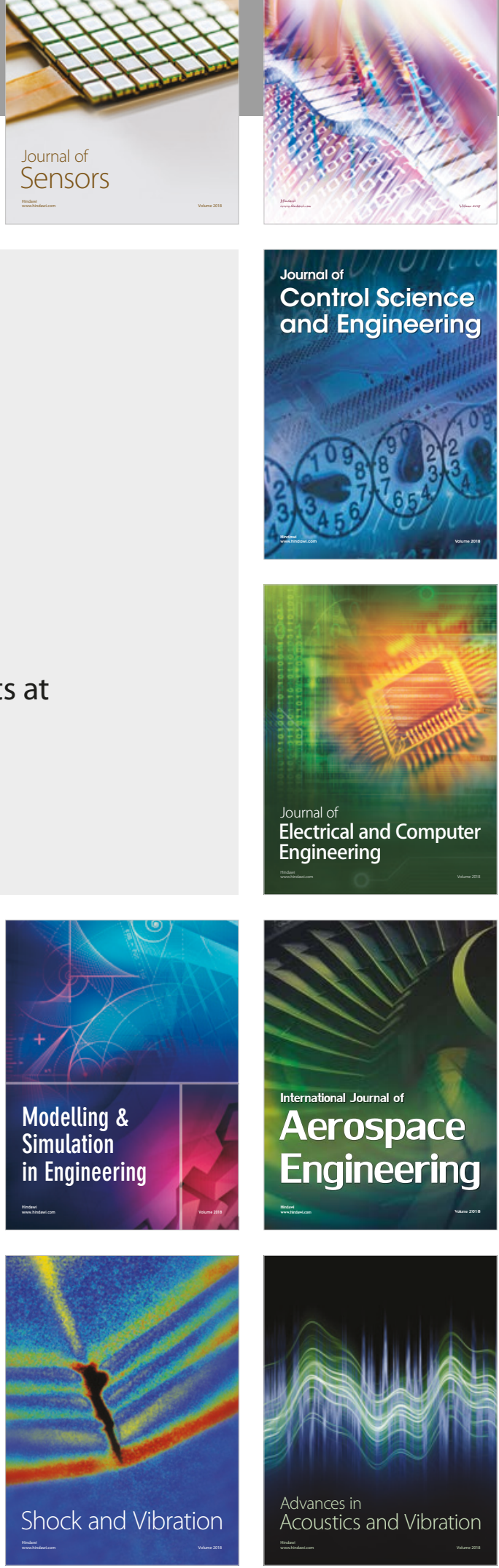